\title{
TENDÊNCIAS E RUPTURAS CLIMATO-HIDROLÓGICAS NO SÍTIO RAMSAR PARNA PANTANAL (MT, BRASIL)
}

TOZATO, Heloisa de Camargo - htozato@gmail.com

Doutoranda do PROCAM-USP/Brasil em co-tutela com o Doutorado em Geografia da Université Rennes 2 (França). Bolsista do Programa Ciências Sem Fronteiras.

DUBREUIL, Vincent - vincent.dubreuil@uhb.fr

Professor Dr. da Université Rennes 2. Pesquisador do Laboratório LETG-Rennes-COSTEL

DE MELLO-THÉRY, Neli Aparecida - namello@usp.br

Professora Dra da EACH/USP. Programas de Pós Graduação PROCAM-USP e PPGH-USP. Pesquisadora do Laboratório GEOPO - Geografia Política (USP-SP).

\begin{abstract}
RESUMO: Com o intuito de contribuir com os estudos climato-hidrológicos no sítio Ramsar PARNA Pantanal, conforme as recomendações da Convenção de Ramsar, o presente trabalho analisou séries anuais de dados observados de chuva, temperatura e cotas fluviométricas no período de 1971 a 2011 de estações da sub-bacia do Alto Paraguai. Os dados foram analisados com os testes de Mann-Kendall e Regressão linear para identificação de tendências e Pettitt para verificação de rupturas. Foram constatados diminuição pluviométrica anual na porção que se estende da Amazônia ao centro do Pantanal e aumento das temperaturas máxima e mínima nas estações de Cáceres (MT) e Cuiabá (MT). O nível $\mathrm{d}^{\prime}$ água dos rios localizados nas Ottobacias responsáveis pela manutenção do sistema hídrico do sítio Ramsar PARNA Pantanal variou no período estudado. O estudo demonstra o alto grau de vulnerabilidade do sítio Ramsar PARNA Pantanal à variabilidade do clima.
\end{abstract}

Palavras-chave: cotas fluviométricas, pluviometria, temperatura, tendências climáticas, zonas úmidas.

TENDENCIES AND RUPTURES CLIMATE-HYDROLOGICAL ON SITIO RAMSAR PARNA PANTANAL (MT-BRAZIL)

ABSTRACT: Aiming to contribute to climate-hydrology studies in PARNA Pantanal Ramsar site according to the recommendations of the Ramsar Convention, the present study examined annual series of observed data of rainfall, temperature and fluviometric quota in the period 1971 to 2011 of sub-basin of the Upper Paraguay River. Data were analyzed with tests Mann-Kendall and Linear Regression to identify trends and Pettitt to check ruptures. The following facts were observed: a decline in annual rainfall in the portion extending from the Amazon to the center of the Pantanal biome and an increased of maximum and minimum temperatures at the stations of Cáceres (MT) and Cuiabá (MT). The water level of the rivers located in Ottobacias responsible for the maintenance of the water system of the Ramsar PARNA Pantanal site varied. This study demonstrates the high degree of vulnerability of the Ramsar site PARNA Pantanal to climate variability.

Key-words: fluviometric quota, rainfall, temperature, climate trends, wetlands.

RESUME: Visant à contribuer à l'étude des variabilités climato-hydrologiques dans le site Ramsar PARNA Pantanal selon les recommandations de la Convention de Ramsar, la présente étude a examiné les séries annuelles de données observées de précipitations, température et niveau d'eau durant la période 1971 à 2011. Les données ont été analysées par les tests de Mann -Kendall et par la Régression Linéaire pour identifier les tendances et par le test de Pettitt pour vérifier ruptures. Il a ainsi été observé une diminution des précipitations annuelles allant de l'Amazonie au centre du Pantanal et une hausse des températures maximales et minimales dans les stations de Cáceres (MT) et Cuiabá (MT). Le niveau d'eau des rivières situées dans Ottobacias qui participe habituellement au maintien du système d'eau du site Ramsar PARNA Pantanal a varié. L'étude démontre le haut degré de vulnérabilité du site Ramsar PARNA Pantanal à la variabilité climatique. 
Mots-clés: niveau d'eau, précipitations, température, tendances climatiques, zones humides.

RESUMEN: Con el objetivo de contribuir con los estudios climato-hidrológicos en la zona de Ramsar PARNA Pantanal, conforme a las recomendaciones de la Convención de Ramsar, el presente trabajo analizó series anuales de datos observados de lluvia, temperatura y cuotas en el periodo de 1971 a 2011 de estaciones de la sub-cuenca de Alto Paraguay. Los datos fueron analizados con la pruebas de Mann-Kendall y Regresión linear para identificación de tendencias y Pettitt para verificación de rupturas. Fueron constatados diminución pluviométrica anual en la porción que se extiende de la Amazonia al centro de Pantanal y aumento de las temperaturas máxima e mínima en las estaciones de Cáceres (MT) y Cuiabá (MT). El nivel de agua de los ríos localizados en las Ottobacias responsables por el mantenimiento del sistema hídrico de la zona Ramsar PARNA Pantanal varió durante el periodo estudiado. El estudio demuestra el alto grado de vulnerabilidad de la zona Ramsar PARNA Pantanal a la variabilidad del clima.

Palabras-clave: cuotas, pluviometría, temperatura, tendencias climáticas, zonas húmedas.

\section{INTRODUÇÃO}

Desde a apresentação dos relatórios do Intergovernmental Panel on Climate Change, IPCC (WATSON et al., 1998, 2000, 2003; METZ, 2001; MCCARTHY, 2001), a Convenção sobre as Zonas Úmidas de Importância Internacional (Convenção de Ramsar) tem discutido as implicações das mudanças do clima nas zonas úmidas. Cientes de que a função ecológica dessas áreas é altamente dependente da qualidade e quantidade do fornecimento da água e que estas são influenciadas direta e indiretamente pelo clima, a preocupação com os impactos nos serviços ecossistêmicos é pauta da agenda de negociações desde 1999.

Os debates resultaram na aprovação dos documentos Resolução VII.27 da COP7 de 1999, Documentos DOC11 e DOC40 e Resoluções VIII.3 e VIII.25 da COP8 de 2002, Documento DOC25 e Resolução X.24 da COP10 de 2008 e Resolução XI.14 da COP11 de 2012. Como prioridade, as nações devem realizar estudos mais detalhados nas escalas regionais e locais no âmbito dos seus sítios Ramsar ${ }^{1}$ (RAMSAR, 2002).

O Brasil, responsável pela gestão do bioma Pantanal, a mais ampla e complexa planície inundável existente na sua faixa de latitude (WILHELMY, 1958), aderiu à Convenção de Ramsar em 1993 e assumiu o compromisso internacional de garantir o uso responsável e de preservar as funções ecológicas de suas zonas úmidas pelo Decreto 1905/96.

Atualmente o país apresenta três sítios Ramsar pantaneiros, sendo o Parque Nacional do Pantanal Matogrossense (PARNA Pantanal) o maior e mais antigo deles (criado em 1993) e o segundo maior da lista de Ramsar brasileira. O desafio da gestão está relacionado à manutenção da dinâmica sazonal de inundação, a qual, segundo Marengo (2006) pode ser modificada drasticamente por conta de alterações do clima.

${ }_{1}^{1}$ Áreas úmidas reconhecidas como de importância internacional pela Convenção de Ramsar. 
De acordo com aquele autor (MARENGO, 2006), em escala regional, o bioma Pantanal apresenta: a) previsão regional de anomalias de chuva (em relação à média de 1961-1990) geradas por seis modelos do IPCC para o período 20002100 da ordem de $-0.5 \mathrm{~mm}$ por dia no cenário A2 e no cenário B2 após 2060 ; b) previsão de redução de 25 a $50 \%$ das descargas das vazões fluviais ao longo do século XXI conforme o resultado do modelo do Hadley Centre HadGEM1; c) previsão do aumento de temperatura de até $6^{\circ} \mathrm{C}$ em 2100 no cenário $\mathrm{A} 2$ e $4.5^{\circ} \mathrm{C}$ no B2.

Embora a importância deste tipo de análise, são os estudos climatológicos em menores níveis de escala que permitem a percepção de correlações mais complexas e interativas entre o sistema climático e a sociedade, uma vez que os elementos da superfície, inclusive a ação antrópica, são mais pronunciados (JESUS, 2008; RIBEIRO, 1993).

Além disso, o retrato local é essencial para a elaboração de instrumentos políticos de governança de ordem social, política e territorial e para a articulação local-nacional-internacional (MELLO-THÉRY, 2011).

Considerando essas informações e ainda que o fator climato-hidrológico do PARNA Pantanal está relacionado com o clima e regimes d'água da sub-bacia do Alto Paraguai (BAP), este trabalho priorizou a escala local e analisou a variabilidade e correlação pluviométrica, de cotas fluviométricas e temperatura de estações localizadas no território de abrangência e regulação das funções ecológicas deste sítio. O período analisado foi 1971 a 2011.

\section{MATERIAIS E MÉTODOS}

\section{Área de estudo}

O Parque Nacional do Pantanal Matogrossense (PARNA Pantanal) localiza-se no município de Poconé (MT) entre as coordenadas 17.26-17.52S e 57.00$57.28 \mathrm{~W}$. Sua zona de amortecimento compreende parte dos municípios de Poconé (MT), Corumbá (MS) e de Cáceres (MT) na fronteira entre Brasil e Bolívia. Apresenta 135.606,47 hectares de área de preservação do Bioma Pantanal na planície fluviolacustre da sub-bacia do Alto Paraguai (BAP) (Figura 1).

A região compreende um denso arranjo de drenagem onde o sistema climático, os solos hidromórficos, a declividade regional inexpressiva, a altimetria (80 a $150 \mathrm{~m}$ ) e a resistência da vegetação contribuem com o lento escoamento da água e proporcionam o aparecimento de ambientes com características próprias, como lagunas, vazantes e baías de diversas dimensões. A paisagem móvel de áreas permanente e temporariamente alagadas é garantida pelas chuvas intermitentes nos rios tributários da BAP (IBAMA, 2003). 


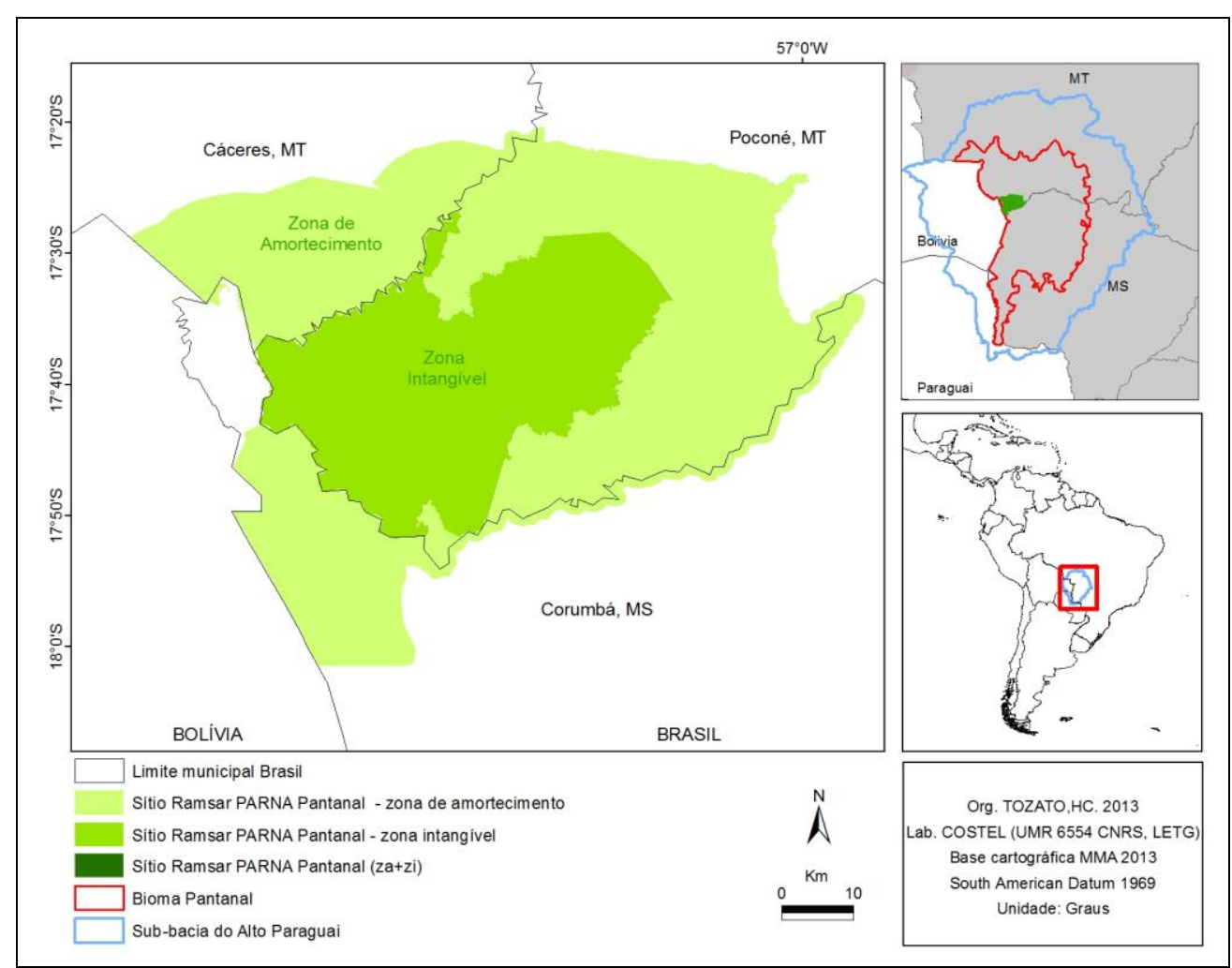

Figura 1. Localização do sítio Ramsar Parque Nacional do Pantanal Matogrossense (PARNA Pantanal) na sub-bacia do Alto Pantanal (BAP) no bioma Pantanal.

Em escala regional, a disposição do conjunto de formas da superfície pantaneira na Depressão Continental do Chaco, no Centro-Oeste brasileiro, é influenciada por trocas atmosféricas meridionais norte-sul e sul-norte (TARIFA, 1986) e pela atuação dos fluxos Tropical, Equatorial e Extratropical na formação do sistema climático (SETTE, 2000).

Há a atuação direta e indireta do $\mathrm{ENSO}^{2}$, da Zona de Convergência do Atlântico Sul (ZCAS) e da Zona de Convergência Intertropical (ZCIT) (SETTE, 2000; DUBREUIL, 2008), do Anticiclone Atlântico, cuja alta pressão regula a estação seca (outono e inverno), e a atuação da convecção da Amazônia, que regula a estação chuvosa (primavera e verão) (ZAVATINI, 1990; SETTE, 2000). Dependendo das frentes associadas aos fluxos polares invasores pelo leste da Cordilheira dos Andes, pode haver condições climáticas mais secas ou chuvosas (ZAVATINI, 1990).

\footnotetext{
${ }^{2}$ Formado pela Oscilação Sul (desvio da pressão atmosférica a partir de uma compensação barométrica entre Pacifico Sul e Oriental), El Niño (TSM - temperatura da superfície do mar acima da média climatológica) e La Niña (TSM - abaixo da média climatológica).
} 
Este sistema proporciona um regime pluviométrico com chuvas entre 800 a $1.500 \mathrm{~mm}$ anuais (TARIFA, 1986), sendo os meses de dezembro, janeiro e fevereiro os mais chuvosos e junho, julho e agosto os mais secos (SALVISAKAMOTO, 2001).

O clima é, portanto, do tipo AW (tropical com estação seca de inverno) com duas estações definidas, a seca (maio a setembro) e a chuvosa (outubro a abril) (ALMEIDA, LIMA, 1959; CAMPOS, 1969).

Segundo Adamoli (1986), embora o clima regional tenha uma atuação em superfícies da ordem de $2.000 .000 \mathrm{~km}^{2}$ no Pantanal, é necessária atenção aos traços climáticos próprios das sub-regiões pantaneiras. Para Garcia e Castro (1986), isso se deve ao resultado da atuação das massas de ar com as complexas interações entre fenômenos inerentes de certas localidades da planície, como topografia, fitogeografia, hidrologia, baixas pressões e altas intensidades de radiações solares. Exemplos são as elevadas pluviometrias anuais da região norte pantaneira $(1.000-1.700 \mathrm{~mm})$, onde há considerável variabilidade na distribuição da pluviosidade e os menores índices encontrados no centro-sul $(1.000-1.100 \mathrm{~mm})$, região em que a variabilidade interanual é pouco acentuada (ZAVATTINI, 1990, 2009).

Corroborando com estas discussões, as estações com séries mais chuvosas encontram-se, na área de estudo desta pesquisa, em menores latitudes, com destaque para a Chapada dos Guimarães (1555001), que apresentou a maior pluviometria anual de 1971 a $2011(\mu=2282 \mathrm{~mm})$. Estações menos chuvosas encontram-se em latitudes maiores que 17.13S, na depressão pantaneira, região onde situa-se 0 sítio Ramsar Parque Nacional do Pantanal Matogrossense. Destaca-se Porto Esperança (1957006), que apresentou a série de menor índice pluviométrico no mesmo período, com valor anual de $\mu=929 \mathrm{~mm}$ (Figura 2). 
ISSN: 1980-055x (Impressa) 2237-8642 (Eletrônica)

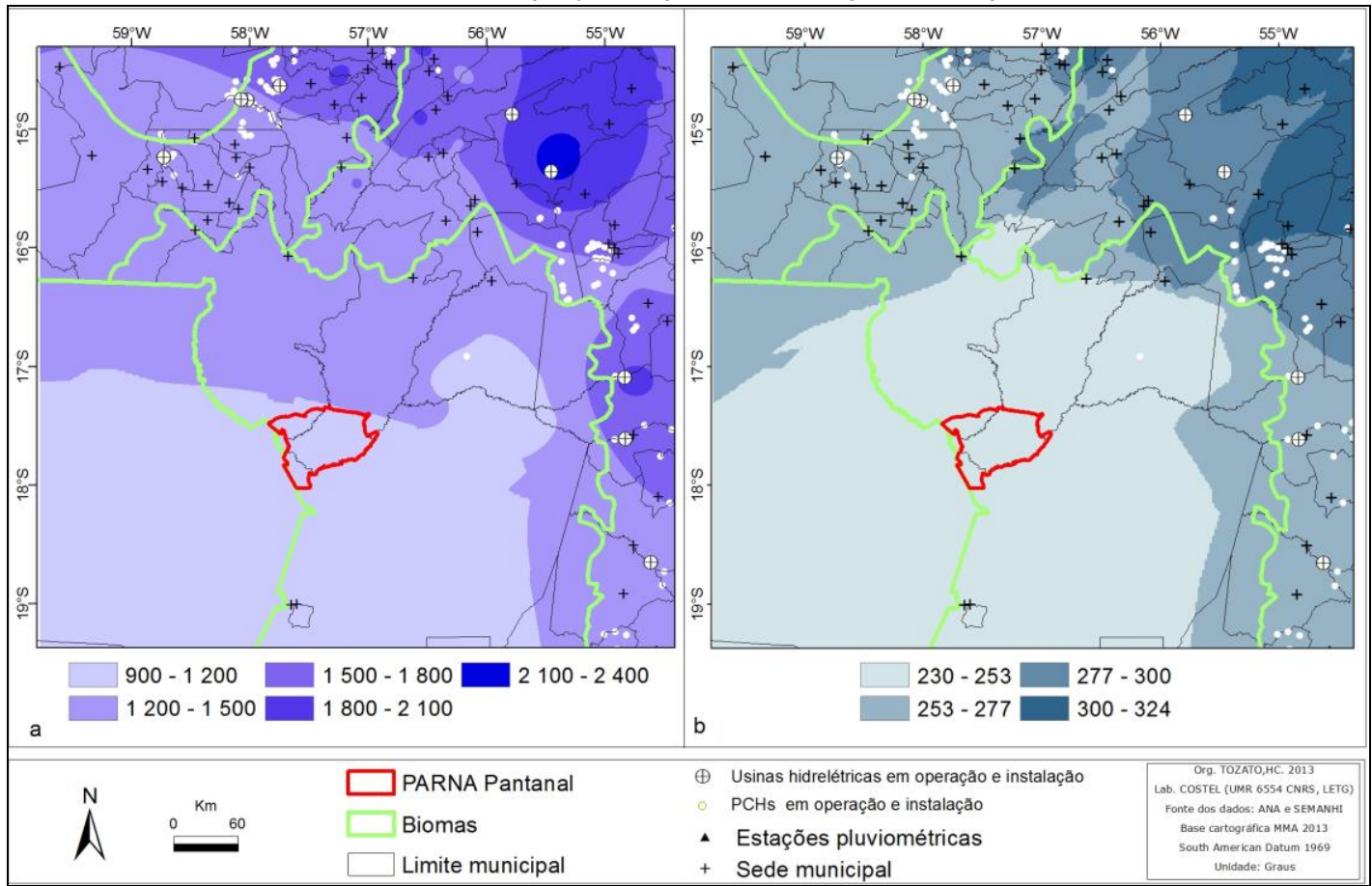

Figura 2. Chuva acumulada na sub-bacia do Alto Paraguai no período de 1971 a 2011. $a=$ pluviometria média anual $(\mathrm{mm}), b=$ desvio padrão da pluviometria média anual ( $\mathrm{mm}$ ).

Séries de dados e análises estatísticas

Foram utilizadas séries históricas anuais, no período de 1971 a 2011, de pluviometria, cotas fluviométricas e temperatura de estações localizadas na BAP, sendo as séries de cotas especificamente de microbacias Ottobacias ${ }^{3}$ nível 3 (896, 897, 898 e 899) que compreendem o interior e região a montante do Parque Nacional do Pantanal Matogrossense.

Ao todo, foram verificadas, no presente trabalho, 203 estações de chuva, 40 estações de cotas e 11 estações de temperatura gerenciadas pela Agência Nacional das Águas do Brasil (ANA), pelo Servicio Nacional de Meteorología e Hidrología da Bolívia (SEMANHI) e pelo Instituto Nacional de Meteorologia do Brasil (INMET) (Figura 3).

Considerando que a presença de dados faltantes ou duvidosos nas séries históricas meteorológicas e hidrológicas é comum em muitas áreas do Brasil ${ }^{4}$, e em especial nos estados do Mato Grosso (DEBORTOLI et al., 2012a), para garantir análises estatísticas consistentes, as séries foram consideradas

\footnotetext{
${ }^{3}$ As unidades territoriais de Ottobacias compreendem um método codificado por Otto Pfafstter em 1989 no âmbito do Programa Nacional de Irrigação (PRONI) do Departamento Nacional de Obras de Saneamento (DNOS) e se baseia na topografia da área drenada e na topologia da rede de drenagem (PFAFSTETTER, 1989). O método foi reconhecido pelo United States Geological Survey (USGS) para a codificação de bacias hidrográficas em todos os países com o apoio da Organização das Nações Unidas (ONU) e no Brasil é utilizado para o estudo e a gestão da Política Nacional de Recursos Hídricos (Lei 9.433/1997) e do Sistema Nacional de Gerenciamento de Recursos Hídricos no Brasil (RUBERT, 2000).

${ }^{4}$ As inconsistências devem-se a deficiências nos instrumentos de medição, a falhas do observador na coleta da informação ou ao desativamento de estações.
} 
apropriadas para o estudo somente quando apresentaram a) mínimo de 30 anos de dados, b) máximo cinco anos consecutivos de dados faltantes na série e, c) máximo dois meses consecutivos de dados faltantes na série anual, os quais foram corrigidos com a média da série histórica mensal dos 30 anos (ou mais) (adaptado de DEBORTOLI et al., 2012b).

O valor mínimo de 30 anos para a análise climática é estipulado pela Organização Mundial de Meteorologia. No período estudado, tal valor garante a utilização de séries históricas com mais de $70 \%$ de dados anuais. O limite de cinco anos faltantes consecutivos assegura que o teste estatístico desconsidere casos incompletos e previne resultados tendenciosos. Por fim, a mínima substituição de dados lacunares objetivou o não enviesamento da base de dados para que os resultados apresentados garantissem um modelo com poder preditivo mais próximo possível da realidade.

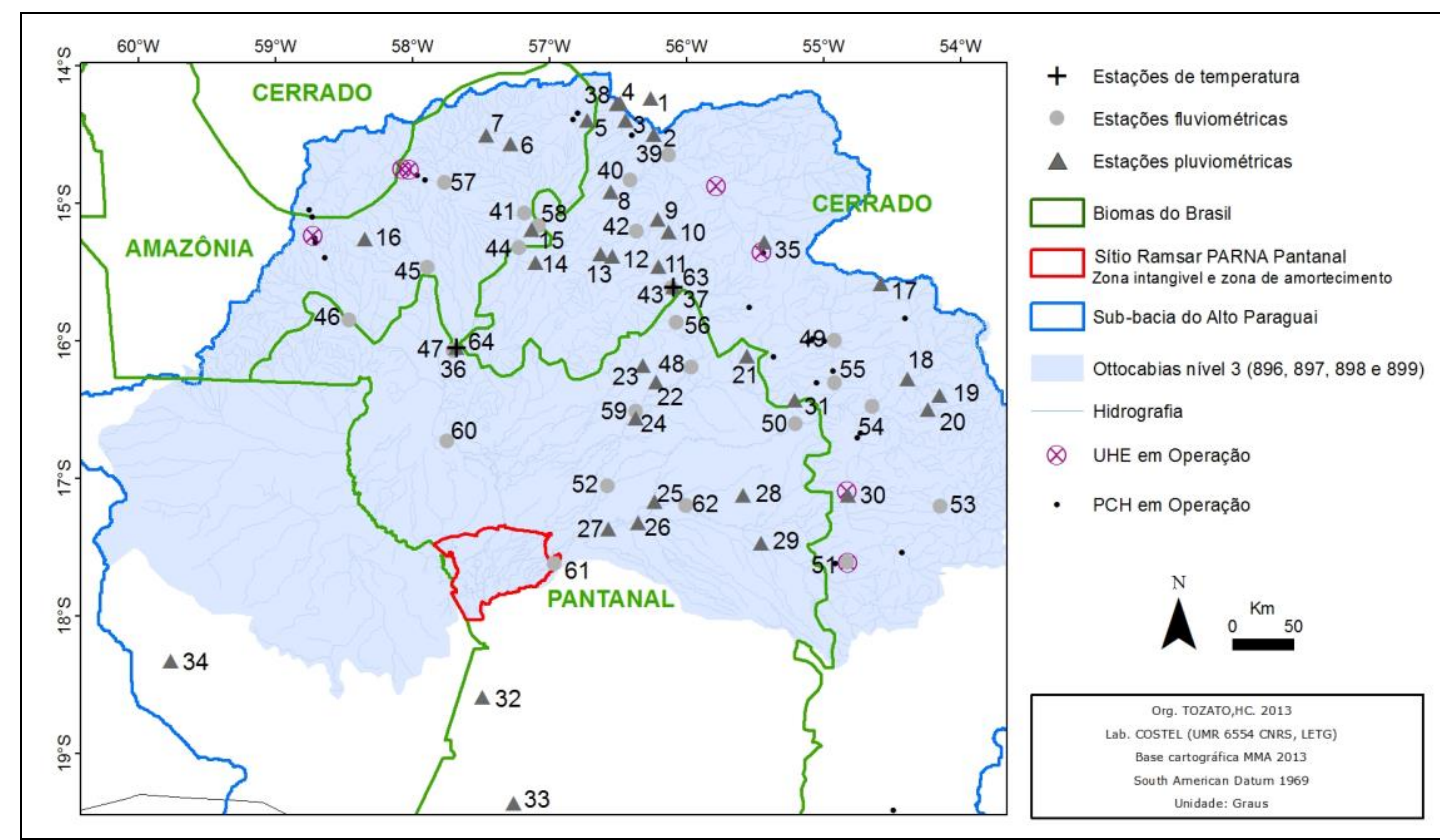

Figura 3. Localização das estações de pluviometria, cotas fluviométricas e de temperatura na subbacia do Alto Paraguai, no bioma Pantanal. 1-38=estações pluviométricas; 39-62=estações fluviométricas; 63-64=estações de temperatura. 1=Diamantino (1456005), 2=Rosário Oeste (1456008), 3=Diamantino (83309), 4=Nortelândia (1456003), 5=Quebo (1456004), 6=Tangara da Serra (1457001), 7=Tapirapuã (1457000), 8=Parecis (1456009), 9=Acorizal (1556005), 10= Nossa Sra da Guia (1556000), 11=Nossa Sra do Livramento (1556001), 12=Seco (1556006), 13=Cuiabá (1556002),14=Barra do Bugres (1557001), 15=Porto Estrela (1557000), 16=Alto Jauru (1558004), 17=Jaciara (1554006), 18=Rondonópolis (1654000), 19=Santa Terezinha (1654001), 20=Santa Escolástica (1654004), 21=Barão de Melgaço (1655002), 22=Porto Cercado (1656001), 23=Poconé (1656002), 24=São João (1656004), 25=São José do Piquiri (1756001), 26=Ilha Camargo (1756000), 27=Porto do Alegre (1756003), 28=São Jerônimo (1725003), 29=União (1755001), $30=$ Itiquira (1754000), 31=Taiamã (1655003), 32=Porto Suarez (1683), 33=Porto Esperança (1957006), 34=Robore (1728), 35=Chapada dos Guimarães (1555001), 36=Cáceres (83405), 37=Cuiabá (83361), 38=Arenápolis (1456001); 39=Quebo (66160000), 40=Rosário Oeste (66250001), 41=Barra do Bugres (66010000), 42=Acorizal (66255000), 43=Cuiabá (66260001), 44=Porto Estrela (66015000), 45=Estrada MT-125 (66065000), 46=Porto Esperidião (66072000), 47=Cáceres (66070004), 48=Barão de Melgaço (66280000), 49=São Pedro da Cipa (66380000), 50=Acima Córrego Grande (66460000), 51=Estrada BR-163(66490000), 52=Ilha Camargo (66370000),53=Itiquira (66520000), 54=Rondonópolis (66450001), 55=São Lourenço de Fatima (66400000), 56=Santo Antônio do Leverger (66270000), 57=Tapirapua (66050000), 58=Jaciara (66008000), 59=Porto Cercado (66340000), 60=Descalvados (66090000), 61=Porto do Alegre (66750000), 62=São Jerônimo (66600000); 63=Cuiabá (83361), 64=Cáceres (83405). 
Das estações verificadas, foram consideradas apropriadas 38 séries de pluviometria (31 da ANA, cinco do INMET e duas do SEMANHI) com $89 \%$ de dados anuais; 24 séries de cotas fluviométricas ( 24 da ANA) com $86 \%$ de dados; e duas séries de temperatura máxima e temperatura mínima ( 2 do INMET) com $76 \%$ de dados. Elas foram espacializadas na Figura 3, sendo 138=estações pluviométricas, 39-62=estações fluviométricas e 63-64=estações de temperatura.

As séries tiveram suas médias, desvios padrão e valores mínimo e máximo calculados e foram submetidas aos testes estatísticos de Pettitt (PETTITT, 1979) para a análise de rupturas anuais e de Mann-Kendall (KENDALL, 1975; MANN, 1945) e Regressão Linear para a análise de tendências (BACK, 2001). O nível de significância adotado foi $5 \%$.

Os coeficientes lineares da série pluviométrica foram espacializados em krigagem ordinária exponencial no Programa ARCGis 10.0 utilizando os valores de decalagem (major range, partial sill, nugget) obtidos pelo semivariograma exponencial no Programa R (RIBEIRO et al., 2006).

Estes testes detectam mudanças na variabilidade dos dados observados e permitem a discussão da contribuição de seus múltiplos fatores causais. Eles têm sido utilizados em estudos de tendências climato-hidrológicas em estações brasileiras localizadas nos Estados da Bahia (MARENGO, 1995), Amazonas (MARENGO, 1995), Rio de Janeiro (MARENGO, 1995; MARENGO, ALVES, 2005), São Paulo (BLAIN et al., 2009; FERRARI et al., 2012), Mato Grosso (DUBREUIL et al., 2012) e Santa Catarina (BLACK, 2001).

\section{RESULTADOS E DISCUSSÃO}

\section{Tendências e rupturas nas séries históricas de temperatura mínima e máxima}

Em escala regional, a temperatura média anual do Pantanal constitui uma grandeza relacionada com o balanço local de radiação, massas de ar, topografia e troca de energia de áreas naturais, como o mosaico de vegetação e de áreas modificadas.

Na escala local, $100 \%$ das séries de temperaturas máxima e mínima de Cuiabá e Cáceres apresentaram tendência de aumento, no período de 1971 a 2011, segundo os coeficientes lineares encontrados.

Em Cuiabá (83301) a elevação das temperaturas mínima e máxima foi também registrada pelo teste de Mann-Kendall ( $p=0.002$ e $p=0.0002$, respectivamente) e pela presença de ruptura positiva em 1984 (aumento de $0.7^{\circ} \mathrm{C}$ e $0.4^{\circ} \mathrm{C}$ em 1984, $p=0.0017$ e $p=0.0002$, respectivamente) (Figura 4a-b). 
Em Cáceres (83405) a série de temperatura mínima registrou tendência positiva $(p<0.0001)$ pelo teste de Mann-Kendall e aumento de $0.5^{\circ} \mathrm{C}$ a partir de 1995 pelo teste de Pettitt $(p<0.0001)$ (Figura 4c).

Nestas áreas, o incremento de temperatura pode relacionar-se à presença de formações vegetais semiabertas do bioma Pantanal (campos, mata seca e bambuzal) onde há maior penetração solar e maior atividade convectiva para transportar o calor das copas ao solo (HOFFMAN, 2008) e à conversão das florestas, por exemplo bosque de cambará em pastos, que passam a fornecer energia excedente para o aquecimento do ar próximo à superfície (BIUDES et al., 2009).

Ressalta-se também a existência de ilhas de calor por conta do processo acelerado de urbanização, quando há mudanças profundas nas condições climáticas locais (DUBREUIL, 2008). Segundo Dubreuil (2008), em Cuiabá elas são acentuadas durante a estação seca, quando há uma diferença média de $3.8^{\circ} \mathrm{C}$ entre as temperaturas da cidade e zona rural contra $1.8^{\circ} \mathrm{C}$ na época das chuvas. O fenômeno acontece devido o aumento do fluxo de calor sensível nas áreas urbanas, manutenção do fluxo de calor latente no limite da área rural e aquecimento das camadas inferiores da atmosfera.
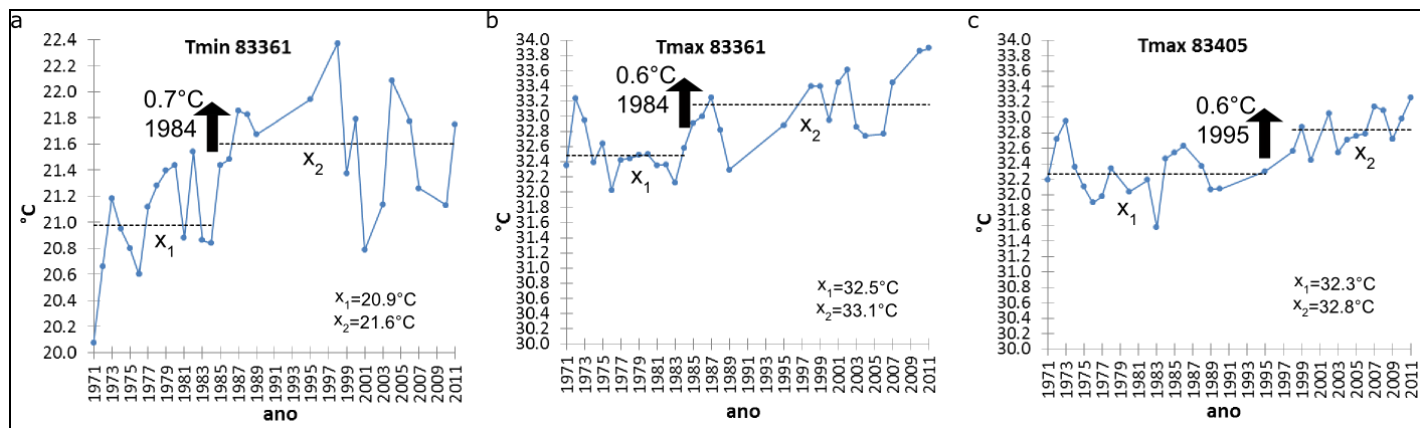

Figura 4. Rupturas nas séries históricas de temperatura média anual $(p<0.05)$ na sub-bacia do Alto Paraguai no período de 1971 a 2011. $\mathrm{x}_{1}=$ temperatura $\left({ }^{\circ} \mathrm{C}\right)$ no período pré-ruptura; $\mathrm{x}_{2}=$ temperatura $\left({ }^{\circ} \mathrm{C}\right)$ no período pós-ruptura. $\mathrm{a}=$ Tmin Cuiabá, $\mathrm{b}=$ Tmax Cuiabá, $\mathrm{c}=$ Tmax Cáceres.

\section{Tendências e rupturas nas séries históricas de chuva}

A Figura 5 apresenta a espacialização da extensão horizontal da tendência pluviométrica na BAP durante esses 41 anos e evidencia que o evento de redução de chuvas aconteceu desde a zona de transição entre AmazôniaPantanal e estendeu-se por toda a planície pantaneira, inclusive na região do sítio Ramsar PARNA Pantanal e Chaco boliviano.

De acordo com o teste estatístico de Mann-Kendall, 16\% das séries históricas de chuva analisadas apresentaram redução $(p<0.05)$ (Figura 5$)$ e segundo os coeficientes de regressão linear esse fenômeno aconteceu em $68 \%$ delas. As informações foram reforçadas pelo teste estatístico de Pettitt, que apontou $24 \%$ de rupturas negativas nas séries de pluviometria acumulada anual $(p<0.05)$ (Figura 5 e Figura 6a-i). 
A diminuição das chuvas foi extremamente acentuada (resultado significativo nos três testes estatísticos empregados) em duas estações ao norte do sítio Ramsar PARNA Pantanal, uma localizada no bioma Cerrado (Acorizal-1556005) e outra no bioma Amazônia (Tapirapuã-1457000), onde houve a maior queda da média pluviométrica anual no período estudado $(-526 \mathrm{~mm})$ e menor coeficiente angular observado ( $a=-14.63)$; e também em quatro estações localizadas no Pantanal, duas a leste do PARNA Pantanal (Porto do Alegre1756003 e São José do Piquiri-1756001) e duas ao sul (Porto Suarez-1683 e Porto Esperança-1957006) (Figura 5, Tabela 1).

Em menor grau, outras nove séries pluviométricas localizadas no bioma Pantanal, duas na Amazônia, uma no Chaco e oito no Cerrado tiveram redução anual do índice de chuva. Elas apresentaram diferentes resultados entre os testes empregados, mas nenhuma incongruência entre as conclusões obtidas (Tabela 1). A diferença entre os resultados dos testes de Regressão Linear, Pettitt e Mann-Kendall era esperada e acontece pelo fato dos coeficientes angulares captarem tendências sutis ao longo da série histórica.

Tabela 1. Síntese de rupturas e tendências (em número absoluto) nas séries históricas de pluviometria acumulada anual $(p<0.05)$ e cota média anual na BAP de 1971 a 2011. $\mathrm{PT}=$ Pettitt, $\quad \mathrm{MK}=$ Mann-Kendall, $\mathrm{RL}=$ Regressão Linear, ${ }_{+}=$positivo, $_{-}=$negativo, ${ }_{0}=$ nulo.

Cotas fluviométricas

\begin{tabular}{lcccccc}
\hline & $\mathbf{P T}_{+}$ & $\mathbf{P T}_{\mathbf{0}}$ & $\mathbf{P T}_{-}$ & $\mathbf{P T}_{+}$ & $\mathbf{P T}_{\mathbf{0}}$ & $\mathbf{P T}-$ \\
$\mathbf{M K}_{+}$ & 1 & --- & --- & 2 & --- & --- \\
$\mathbf{R L}_{+}$ & 3 & 9 & --- & 4 & 6 & --- \\
$\mathbf{R L}-$ & --- & 19 & 7 & --- & 3 & 11 \\
$\mathbf{M K}_{-}$ & --- & 3 & 3 & --- & -- & 9 \\
\hline
\end{tabular}




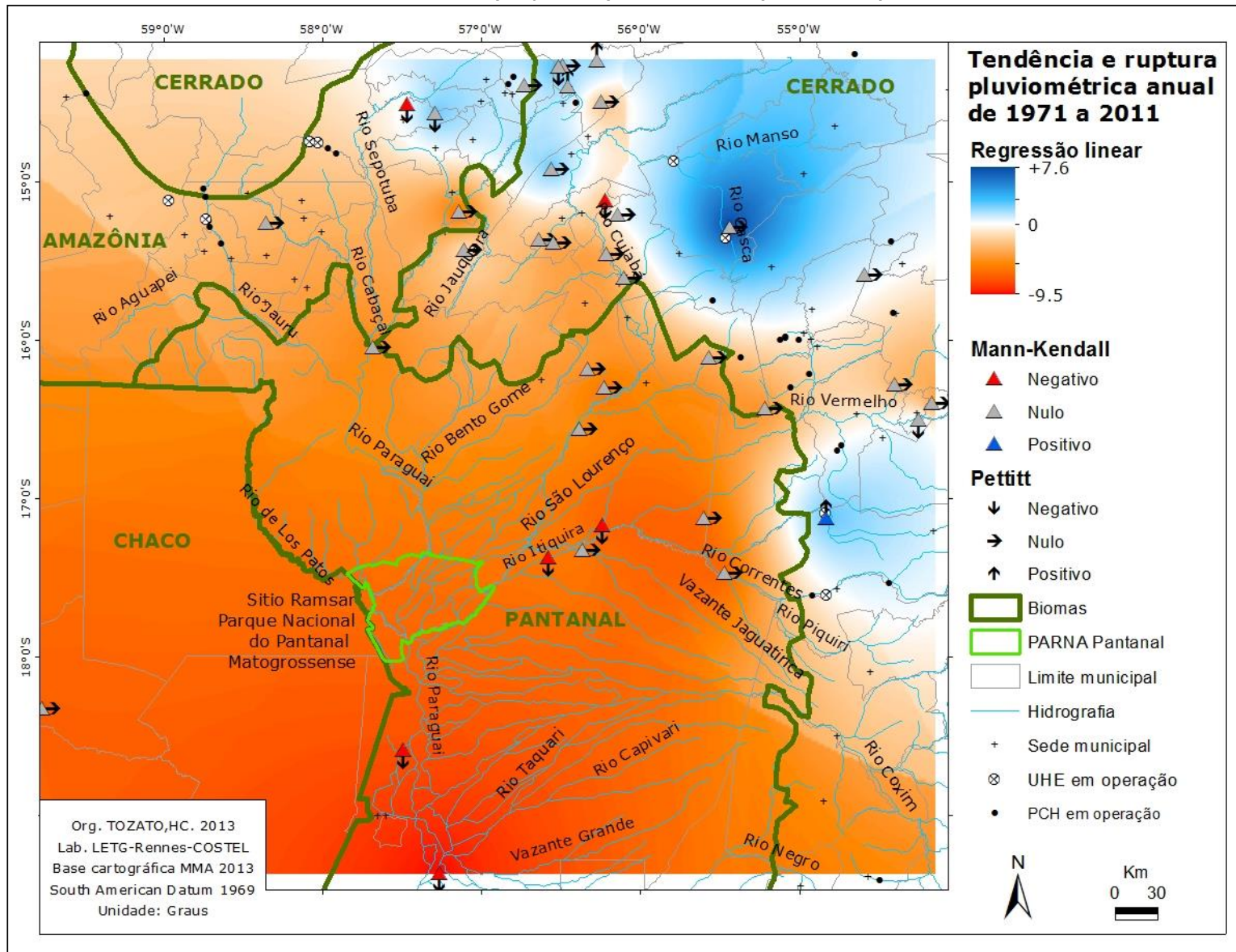

Figura 5. Tendências (resultados dos testes de Mann-Kendall e Regressão Linear) e rupturas (Pettitt) positivas, negativas e nulas de séries anuais de pluviometria total na sub-bacia do Alto Paraguai durante o período de 1971 a 2011.

Salati et al., (1991) discutem que a redução de chuvas e o aquecimento no bioma Pantanal podem estar relacionados com o desmatamento da Amazônia, uma vez que a retirada da floresta amazônica altera as condições climáticas locais e regionais. Nessas escalas, a vegetação fornece umidade atmosférica para 56\% das chuvas (SETTE, 2000), utiliza entre 80 a $90 \%$ da energia radiativa disponível na evapotranspiração e deixa entre 10 a 20\% para o aquecimento do ambiente (DEMANGEOT, 1999).

De acordo com Gomes et al. (2012), o desequilíbrio climático e bioquímico de Cuiabá (MT) é causado, além do desmatamento, pelas queimadas no norte do estado do Mato Grosso devido a devolução de toneladas de $\mathrm{CO}_{2}$ na atmosfera, emissões de metano $\left(\mathrm{CH}_{4}\right)$ e de $\mathrm{NO}_{x}$. Sejam queimadas de cerrado, pastagem ou floresta, as partículas, que resistem por volta de sete dias na atmosfera, podem ser enviadas à troposfera e transportadas ao redor de 4-5 milhões de $\mathrm{km}^{2}$ da fonte (FREITAS et al., 2005).

Um dos corredores de exportação continental de fumaça na América do Sul proveniente de queimadas na Amazônia transporta material particulado na 


\section{ISSN: 1980-055x (Impressa) 2237-8642 (Eletrônica)}

porção norte e oeste do sítio Ramsar PARNA Pantanal. De acordo com o cálculo de Freitas et al. (2005), são depositados $9-90 \mathrm{mg} / \mathrm{m}^{2}$ de material particulado na porção oeste das Ottobacias responsáveis pela drenagem do PARNA Pantanal causando alteração dos ciclos biogeoquímicos naturais e da dinâmica de nutrientes nas regiões emissoras e receptoras.

Foram também observadas, no presente estudo, rupturas positivas nas estações pluviométricas de Diamantino $(1456005 / 83309)(p=0.012 / p=0.0009)$ e Itiquira (1754000) $(p=0.0119)$, ambas no Bioma Cerrado. Nesta, foi constatado aumento da série de chuva pelo teste de Mann-Kendall $(p=0.0011)$ (Figura $6 \mathrm{j}-\mathrm{I}$ ). Outras seis séries pluviométricas localizadas no Cerrado e duas na Amazônia (em região fronteiriça com o Cerrado) também apresentaram aumento do índice de chuva no período de 1971 a 2011, embora em menor grau (Figura 5).

A região do Cerrado apresenta uma dinâmica de chuvas diferenciada. Este espaço é definido por fatores geográficos naturais de maior variabilidade altimétrica, como os Planaltos e Serras do Alto rio Paraguai/Guaporé, Depressão do Alto rio Paraguai/Guaporé, Planalto dos Guimarães e Planalto de Maracaju e que interferem na circulação atmosférica, conforme discute Dubreuil (2008). Segundo o autor (2008), na região da Chapada dos Guimarães há uma relação direta entre altitude e pluviometria, de forma que o gradiente pluviométrico cresce na ordem de $110 \mathrm{~mm}$ a cada $100 \mathrm{~m}$ de altitude. 
ISSN: 1980-055x (Impressa) 2237-8642 (Eletrônica)

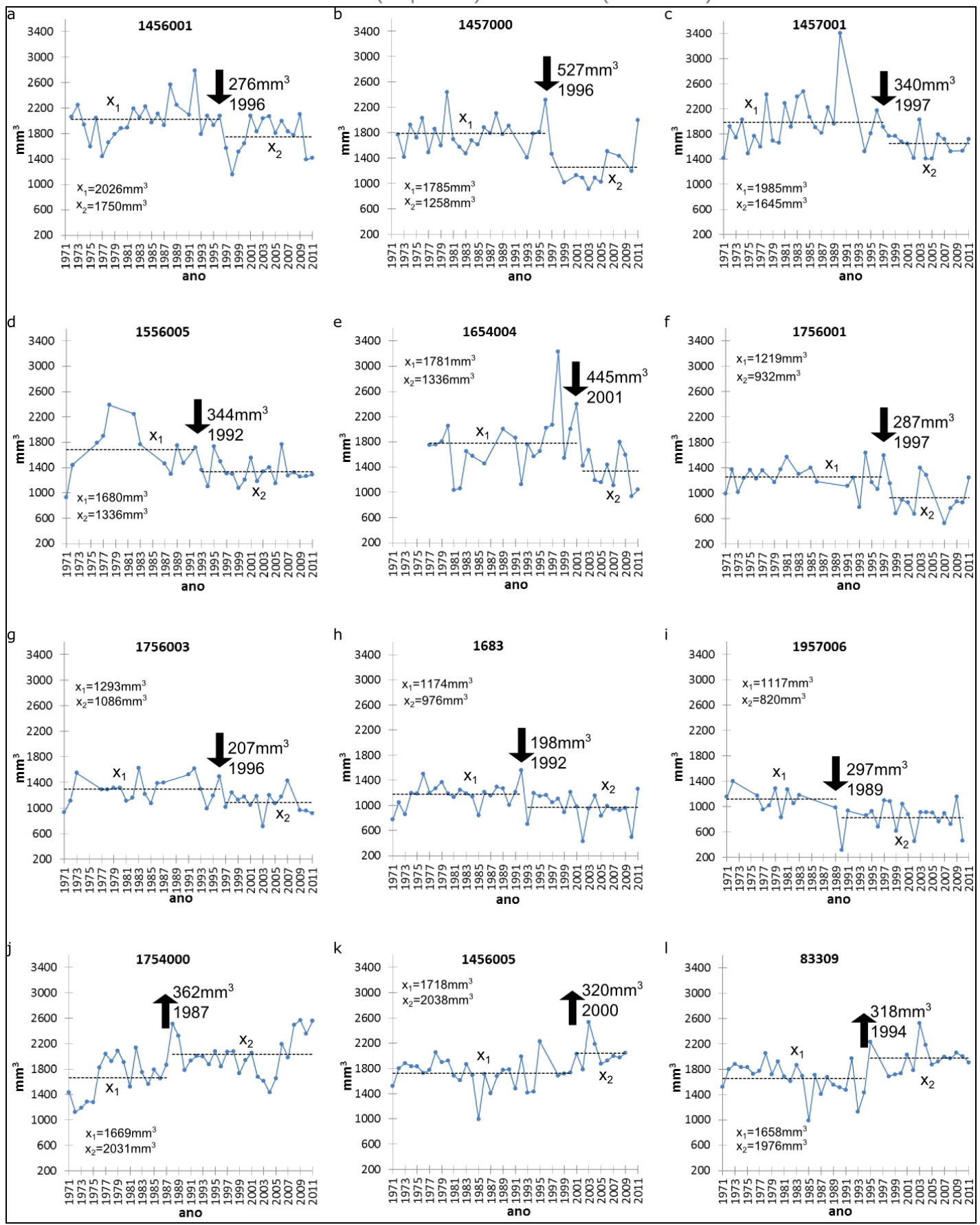

Figura 6. Resultados das rupturas nas séries históricas de pluviometria acumulada anual $(p<0.05)$ na BAP de 1971 a 2011. $x_{1}=$ pluviometria média $(\mathrm{mm})$ no período pré-ruptura; $\mathrm{x}_{2}=$ pluviometria média $(\mathrm{mm})$ no período pósruptura. $a-i=$ ruptura negativa; $j-I=$ ruptura negativa.

Tendências e rupturas nas séries históricas de cotas fluviométricas 
A análise de coeficientes lineares das séries anuais de cotas fluviométricas no interior e a montante do sítio Ramsar PARNA Pantanal indicou que, no período de 1971 a 2011, o nível da água diminuiu em 58\% das estações, sendo que em $8 \%$ delas a tendência foi significativa pelo teste de Mann-Kendall $(p<0.05)$ e em $46 \%$ houve rupturas negativas $(p<0.05)$. Destas, duas apresentaram rupturas negativas durante a década de 80 , nove durante a década de 90 e uma em 2004 (Figura 7a-k).

A diminuição do nível d'água foi extremamente acentuada nas séries históricas da estação fluviométrica Estrada MT-125 (66065000) no bioma Amazônia; Acorizal (66255000), Cuiabá (66260001) e São Pedro da Cipa (66380000) no Cerrado; Cáceres (66070004), Barão de Melgaço (66280000), Acima Córrego Grande (66460000) e Ilha Camargo (66370000) no Pantanal (Figura 8).

Por outro lado, as séries de cotas fluviométricas das estações Rondonópolis (66450001) e São Lourenço de Fatima (66400000) em rios do Cerrado apresentaram relevante aumento do nível d'água (resultado significativo nos três testes estatísticos empregados) (Figura 8). Outras duas na Amazônia, uma no Cerrado e cinco no Pantanal exibiram tendência de aumento em menor grau (Figura 8, Figura 7l-o e Tabela 1).

Esses resultados exibem um cenário de variabilidade do índice de cota anual nos rios da região. O rio Paraguai apresentou diminuição das cotas anuais a partir do município de Tangará da Serra, na fronteira do Cerrado e Amazônia, até a região pantaneira ao norte de Cáceres. Entretanto, à medida que o Paraguai adentra o município, as cotas tornaram a aumentar.

De forma semelhante no bioma Pantanal, o rio Cuiabá apresentou diminuição do nível d'água na porção norte do município de Barão de Melgaço, leve aumento na estação de Porto Cercado (66340000) e diminuição na estação de Ilha Camargo (66370000). Conforme o rio adentrou o município de Corumbá e associou-se com as águas do rio São Lourenço, o índice de cotas aumentou novamente na estação Porto do Alegre (66750000), na porção leste do sítio Ramsar PARNA Pantanal.

Essa variação é decorrente, além das variações interanuais de chuva (CLARKE et al., 2003), pela geomorfologia (HAMILTON, 2002), outros componentes do ciclo hidrológico e influências antrópicas (KREPPER et al., 2006). Cada componente introduz efeitos próprios ao escoamento e equilíbrio dos rios em um processo não linear (KREPPER et al., 2006). 
Revista Brasileira de Climatologia

ISSN: 1980-055x (Impressa) 2237-8642 (Eletrônica)

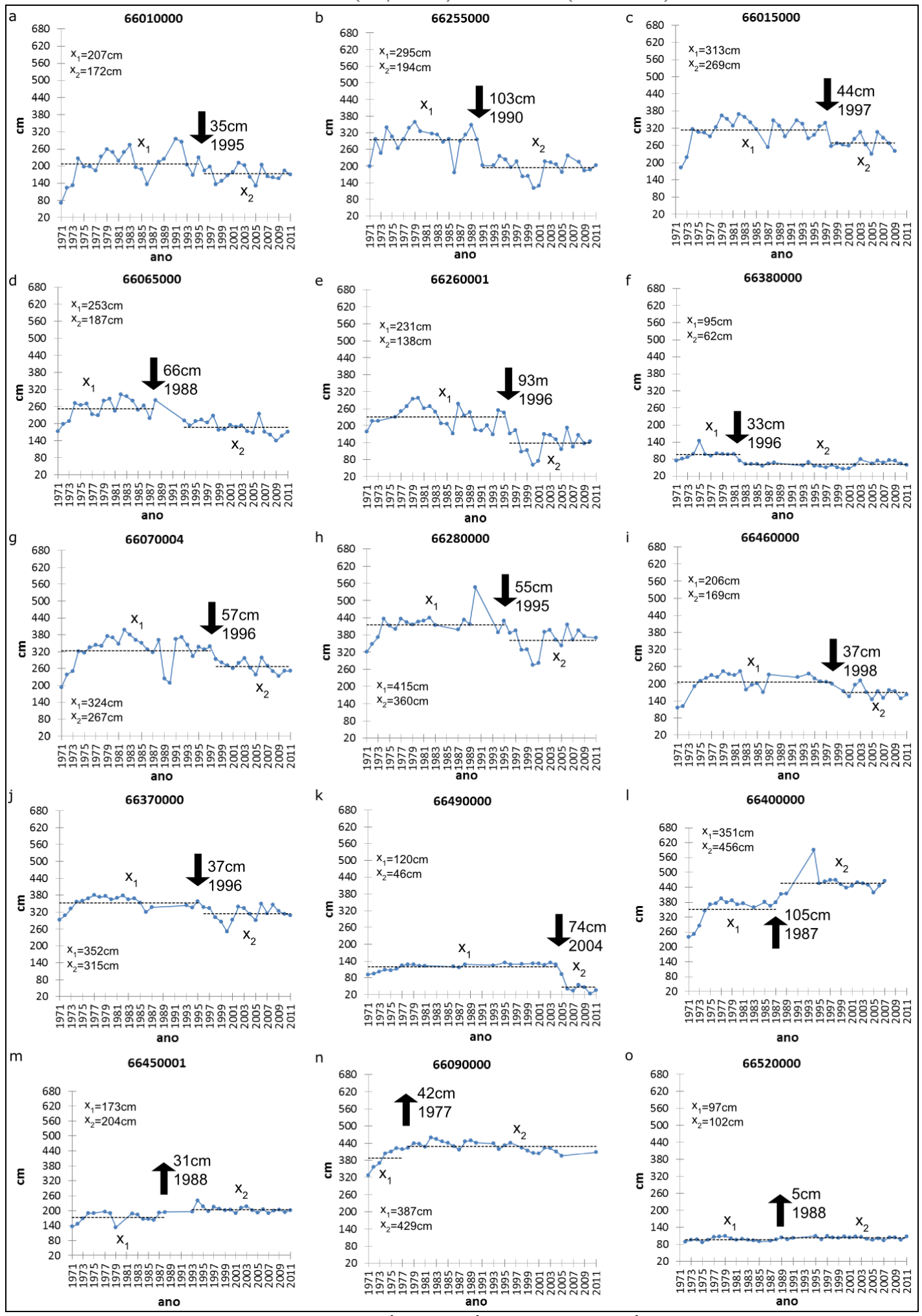

Figura 7. Resultados das rupturas nas séries históricas de cota média anual $(p<0.05)$ na região interior e a montante do sítio Ramsar PARNA Pantanal de 1971 a 2011. $x_{1}=$ cota média $(\mathrm{cm})$ no período pré-ruptura; $x_{2}=$ cota média $(\mathrm{cm})$ no período pós-ruptura. a-k=ruptura negativa; I$0=$ ruptura positiva. 
Um fator que deve ser considerado é a modulação dos regimes hidrológicos dos rios pela existência de barragens. Estas, construídas para irrigação, geração de energia hidrelétrica, fornecimento de água para criações e controle das cheias, causam relevantes impactos cumulativos na condição da vazão, carga e composição dos sedimentos fluviais, principalmente a jusante da instalação.

Na sub-bacia do Alto Paraguai há, atualmente, sete usinas hidrelétricas em operação: Casca III (em operação desde 1970) e Manso (em operação desde 2000) no município Chapada dos Guimarães; Juba I e Juba II (ambas em operação desde 1995) em Barra do Bugres; Ponte de Pedra (em operação desde 2005) e Itiquira (em operação desde 2002) em Itiquira; e Jauru (em operação desde 2003) em Indiavaí. Há ainda 19 Pequenas Centrais Hidrelétricas (PCHs) operando desde 2002. Outras três usinas e 114 PCHs estão em fase de aprovação.

Ressalta-se que $100 \%$ desses empreendimentos em operação encontram-se na região hidrológica responsável pelo sistema hídrico do sítio Ramsar PARNA Pantanal (Figura 2).

Se por um lado a construção da barragem da usina de Itiquira pode auxiliar a explicar a manutenção do aumento de $5 \mathrm{~cm}$ na altura da água na estação fluviométrica de Itiquira (66520000) desde 1988 (a montante da barragem), a construção das hidrelétricas de Juba I e Juba II ajudam a explicar a manutenção da queda da cota da estação de Estrada MT-125 (66065000) ($66 \mathrm{~cm})$ e a diminuição da cota em Cáceres $(66070004)(-57 \mathrm{~cm})$, ambas a jusante das instalações. Da mesma forma, as hidrelétricas de Casca III e Manso auxiliam na explicação da manutenção da perda de $103 \mathrm{~cm}$ do nível da água em Acorizal (66255000) e de 93cm na estação de Cuiabá (66260001) nesses 41 anos (Figura 7, Figura 8).

A construção de uma usina provoca, além da alteração do fluxo hídrico, mudanças no uso e ocupação do solo da bacia em questão. Segundo Le Strat et al. (2011), a construção do reservatório pode apresentar multifinalidades, como suporte para atividades agropecuárias e recreação. De acordo com os autores, no caso da bacia hidrográfica do rio Manso, onde houve a instalação da UHE de Manso, houve aumento de $108 \%$ das áreas de pastagens e diminuição de $38 \%$ das áreas de Cerrado e florestas em 17 anos.

Por esses motivos e ainda considerando a infestação de mexilhão dourado (Limnoperna fortunei) e outros moluscos nativos ou exóticos, a garantia de passagens para peixes, etc nos rios pantaneiros, Calheiros et al., (2009) apresentam recomendações para o gerenciamento de geração de energia na sub-bacia do Alto Paraguai. 
ISSN: 1980-055x (Impressa) 2237-8642 (Eletrônica)

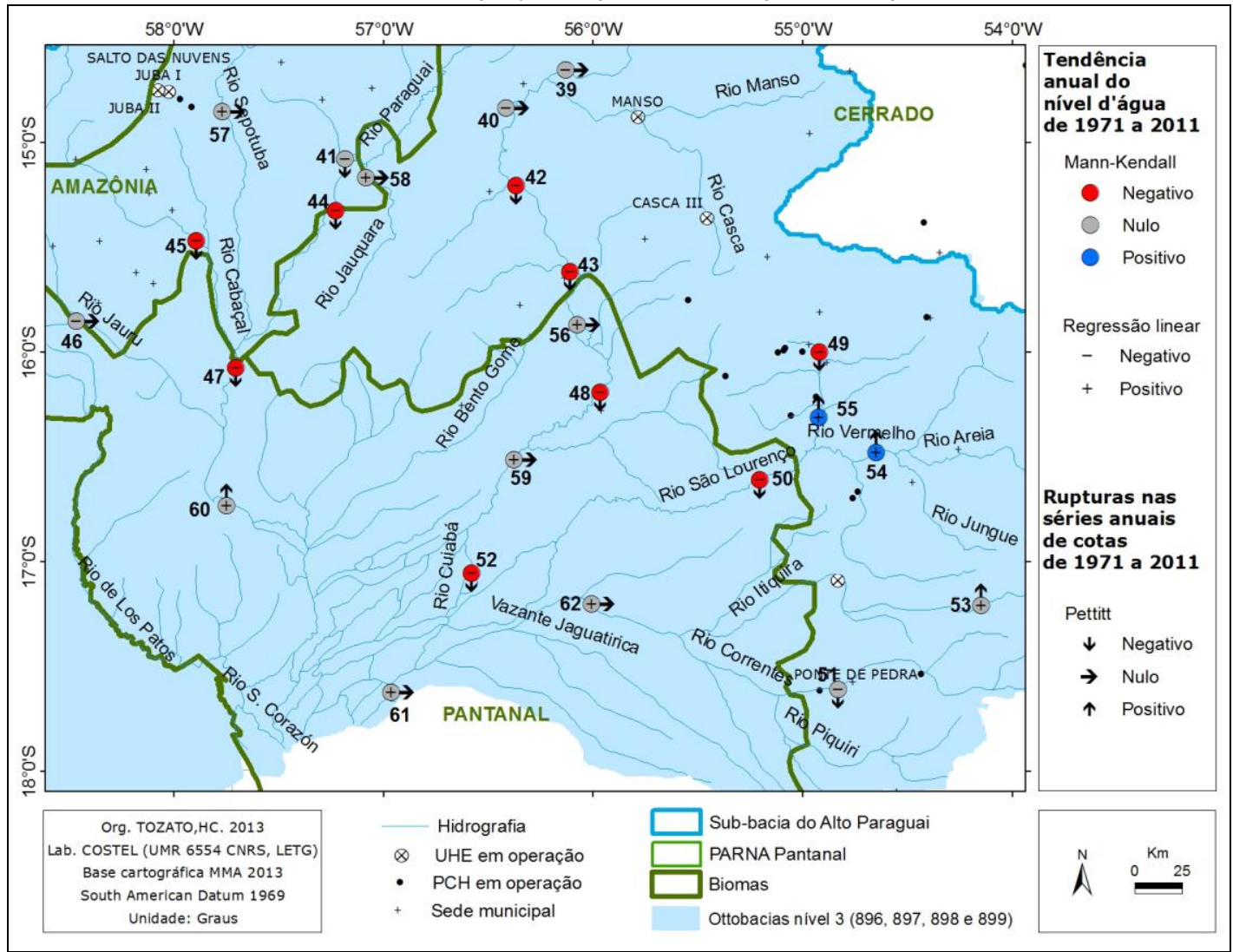

Figura 8. Tendências (resultados dos testes de Mann-Kendall e Regressão Linear) e rupturas (Pettitt) positivas, negativas e nulas de séries anuais de cota fluviométrica média na região do sítio Ramsar PARNA Pantanal no período de 1971 a 2011. 39-62=estações fluviométricas. $\mathrm{p}<0.05$.

\section{CONCLUSÕES}

O presente estudo evidenciou o cenário de diminuição pluviométrica anual durante 1971 a 2011 nas porções norte e centro pantaneiras, localizadas entre as coordenadas 59.24-59.26W e 15.49-19.36S. Ressalta-se que, quanto mais ao sul e a oeste, inclusive no Chaco boliviano, maior foi a redução dos totais pluviométricos anuais.

Ao mesmo tempo, houve aumento das temperaturas máxima e mínima nos municípios de Cáceres (MT), o qual compreende parte da zona de amortecimento do sítio em estudo e de Cuiabá (MT), ambos no Pantanal matogrossense.

A tendência de redução de chuva e aumento da temperatura no Pantanal foi concomitante à diminuição do nível da água nos rios São Lourenço, Cuiabá e Paraguai no Pantanal, sistemas hídricos de manutenção do sítio Ramsar Parque Nacional do Pantanal Matogrossense.

Devido o efeito de outros fatores reguladores do sistema hídrico estudado (como características geomorfológicas, evapotranspiração, demais componentes do ciclo hidrológico e influências antrópicas), a variabilidade climática parece ser responsável apenas por parte da variação dos índices de 
cotas fluviométricas encontrada, uma vez que houve aumento do nível da água em alguns rios. O evento abre a possibilidade para novos estudos como, por exemplo, o cruzamento dos resultados encontrados com as variáveis de períodos El Niño - La Niña para aprofundar seu entendimento e ainda a análise de imagens de satélite TRMM ou GPM para melhorar a cobertura espacial de dados de temperatura nessa região com poucas estações de séries completas.

De qualquer maneira, a heterogeneidade e a diversidade de ambientes, os quais incluem ecossistemas do domínio dos cerrados e Chaco, além de componentes bióticos do Nordeste seco e da região periamazônica ( $A B$ 'SABER, 2006) encontram-se em fase de transformação devido a elementos intrínsecos e extrínsecos. As complexas e interativas relações entre o sistema climatohidrológico regional-local e a sociedade têm desenhado, nas últimas décadas, um cenário seletivo onde a manutenção das funções ecológicas depende da resiliência do ecossistema.

Segundo a Convenção sobre as Zonas Úmidas de Importância Internacional (Convenção de Ramsar), os impactos deste arranjo são potencialmente mais agressivos às zonas úmidas que os efeitos exclusivos de cada uma das variáveis envolvidas. Exemplo disto é a provável modificação dos serviços ecossistêmicos ao longo desses 41 anos e interferência na fenologia de aves migratórias neárticas, como Pandion haliaetus (Águia-pescadora), Actitis macularius (Bate-bunda), Tringa solitaria (Maçariquinho) e Tringa flavipes (Maçarico) e peixes migratórios neotropicais e no favorecimento de organismos com maior plasticidade ecológica, como Limnoperna fortunei (mexilhão dourado) e Brachiaria subquadripara (capim) (TOZATO et al., 2012, CALHEIROS et al., 2009, BAILLY, 2006, IBAMA, 2003) no PARNA Pantanal. Por outro lado é preciso considerar que esse cenário pode favorecer a expansão do território utilizado pela pecuária no bioma, principal atividade econômica pantaneira e relevante vetor de pressão.

Discussão semelhante é válida para outras áreas protegidas localizadas na região pantaneira avaliada no presente estudo, em especial o Parque Estadual do Guirá, o ESEC de Taiamã, o Parque Estadual Encontro das Águas, a RPPN Fazenda Acurizal e Fazenda Penha, a RPPN Fazenda Dorochê, a RPPN Jubran e a RPPN Estância Ecológica SESC Pantanal. Esta última constitui sítio Ramsar brasileiro desde 2002.

Destaca-se que as áreas protegidas RPPN Reserva Natural Eliezer Batista, RPPN Arara Azul e RPPN Santa Helena também se localizam em região onde houve diminuição pluviométrica durante 1971 a 2011.

De acordo com o Decreto 1905/1996 assinado pelo governo brasileiro, são esperadas politicas convergentes de ordenamento territorial para a conservação das características ecológicas dos sítios Ramsar. Considerando que uma das prioridades é a redução significativa de estressores não climáticos para aumentar a resiliência dos habitats e espécies, conforme a Recomendação COP10 DOC25 da Convenção de Ramsar esperam-se ações de mitigação e adaptação que promovam a manutenção da diversidade, o gerenciamento de corredores ecológicos, o fomento à compreensão dos sistemas sócio-ecológicos como sistemas adaptativos complexos, o incentivo a pesquisas, a ampliação da 
participação, a promoção de governanças policêntricas, e a promoção do respeito e cumprimento da legislação aplicada à zona de amortecimento.

Os resultados do presente estudo também corroboram e reiteram, em escala local, as previsões de alterações climato-hidrológicas apresentadas por Marengo (2006) para o bioma Pantanal e evidenciam a vulnerabilidade e fragilidade do maior sítio Ramsar pantaneiro, o PARNA Pantanal.

\section{AGRADECIMENTOS}

Ao PROCAM-USP, ao IEE-USP, à PPG-USP, ao Laboratório GECA-UFMT, à I'Ecole Doctorale SHS de I'Université Rennes 2 (França) e ao Laboratório COSTEL (França). Aos Programas CAPES-PDSE (processo 5447119), Ciências Sem Fronteiras (processo 246239/2012-3) e USP-COFECUB (processo Uc/Sh 131-11). O presente artigo foi elaborado a partir da tese de doutorado da primeira autora.

\section{REFERÊNCIAS BIBLIOGRÁFICAS}

AB'SABER, A.N. Brasil, paisagens de exceção: o litoral eo Pantanal Mato-grossense, patrimônios básicos, v.2, Ateliê Editorial, 2006, 187p.

ADAMOLI, J. A dinâmica das inundações no Pantanal. In: Simpósio Sobre Recursos Naturais e Sócio-Econômicos do Pantanal, v.1, 1986.

ALMEIDA, F.F.M. de; LIMA, M.A. de. Planalto centro-ocidental e Pantanal matogrossense. Guia de excursão no 1. In: Congresso Internacional de Geografia, v.18, 1959.

BACK, A.J. Aplicação de análise estatística para identificação de tendências climáticas. Pesq. agropec. bras., v. 36, n. 5, p. 717-726, 2001.

BAILLY, D. Influência do regime de cheias na reprodução de espécies com diferentes estratégias reprodutivas da planície de inundação do rio Cuiabá, Alto Pantanal, Brasil, Dissertação de Mestrado, Universidade Estadual de Maringá, 2006.

BIUDES, M.S.; CAMPELO JÚNIOR, J.H. NOGUEIRA, J.S.; SANCHES, L. Estimativa do balanço de energia em cambarazal e pastagem no norte do Pantanal pelo método da razão de Bowen. Revista Brasileira de Meteorologia, v.24, n.2, p.135-143, 2009.

BLACK, A.J. Aplicação de análise estatística para identificação de tendências climáticas. Pesquisa Agropecuária Brasileira, v.36, n.5, p.717-726, 2001.

BLAIN, G.C.; PICOLI, M.C.A.; LULU, J. Análises estatísticas das tendências de elevação nas séries anuais de temperatura mínima do ar no estado de São Paulo. Bragantia, v.68, n.3, p.807-815, 2009.

CALHEIROS, D.F.; ARNDT, E.; RODRIGUEZ, E.; SILVA, M. D. A. Influências de usinas hidrelétricas no funcionamento hidro-ecológico do Pantanal Mato-Grossenserecomendações. Corumbá: Embrapa Pantanal, 2009, 21p.

CAMPOS, F.V. de. Retrato de Mato Grosso. São Paulo: Brasil-Oeste, 1969.

CLARKE, R.T.; TUCCI, C.E.M.; COLLISCHONN, W. Variabilidade temporal no regime hidrológico da bacia do rio Paraguai. Revista brasileira de recursos hídricos. v.8, n.1, p.201-211, 2003.

DEBORTOLI N., DUBREUIL V., DELAHAYE F., RODRIGUES FILHO S. Análise temporal do período chuvoso na Amazônia meridional brasileira (1971-2010). X SBCG - Simpósio Brasileiro de Climatologia Geográfica, 2012a.

DEBORTOLI, N.; DUBREUIL, V.; HEINKE, C.; RODRIGUES FILHO, S. Tendances et ruptures des séries pluviométriques dans la région méridionale de l'Amazonie brésilienne. Actes du 25e Colloque de l'Association Internationale de Climatologie, p. 201-206, 2012b. 
DEMANGEOT J. Tropicalité, géographie physique intertropicale. Paris: A. Colin, 1999, 340p.

DUBREUIL, V. Climats et pionniers du Mato Grosso : apport des données satellitaires et de la modélisation pour le suivi des interactions nature/société dans une région de front pionnier de I'Amazonie brésilienne. Dossier pour l'habilitation à diriger des recherches, Université de Rennes2, 2008, 230p.

DUBREUIL, V.; DEBORTOLI, N.; FUNATSU, B.; NÉDÉLEC, V.; DURIEUX, L. Impact of land-cover change in the Southern Amazonia climate: a case study for the region of Alta Floresta, Mato Grosso, Brazil. Environmental monitoring and assessment. n.184, v.2, p.877-891, 2012.

FERRARI, A.L.; VECCHIA, F.A.S.; COLABONE, R.O. Tendência e variabilidade anuais da temperatura e da pluviosidade em Pirassununga-SP. Revista Brasileira de Climatologia, v.10, p.30-46, 2012.

FREITAS, S.R; LONGO, K.M.; DIAS, M.A.F.S.; DIAS, P.L.S. Emissões de queimadas em ecossistemas da América do Sul. Estudos Avançados, n.19, v.53, p.167-185, 2005.

GARCIA, C.E.A.; CASTRO, R.L.H. Análise da frequência de chuva no Pantanal matogrossense. Pesquisa Agropecuária Brasileira, v.9, n.21, 1986.

GOMES, F.J.D.; SANCHES, L.; ALVES, M.C.;NOGUEIRA, M.C.J.A.; NOGUEIRA, J.S. The

Relationship between Meteorological Variables and Clearness Index for Four

Urban/Suburban Areas of Brazilian Cities. Journal of Environmental Science and

Engineering. p.890-900, 2012.

HAMILTON, S.K. Hydrological controls of ecological structure and function in the Pantanal Wetland (Brazil). In: The Ecohydrology of South American Rivers and Wetlands: International Association of Hydrological Sciences, v.6, p.133-158, 2002.

INSTITUTO BRASILEIRO DO MEIO AMBIENTE E DOS RECURSOS NATURAIS RENOVÁVEIS (IBAMA). Plano de Manejo Parque Nacional do Pantanal Matogrossense, 2003, 543p.

JESUS, E.F.R. Algumas reflexões teórico conceituais na climatologia geográfica em mesoescala: uma proposta de investigação. GeoTextos, v.4, n.1 e 2, p.165-187, 2008.

KENDALL, M. Multivariate Analysis. London: Charles Griffin \& Company, 1975.

KREPPER, C.M.; GARCIA, N.O.; JONES, P.D. Paraguay river basin response to seasonal rainfall. International Journal of Climatology, v.26, p.1267-1278, 2006.

LE STRAT, A.; SANTOS, J.W.M.C.; DUBREUIL,V. Avaliação das mudanças de uso do solo na bacia hidrográfica do rio Manso-MT- Brasil. Anais XV Simpósio Brasileiro de Sensoriamento Remoto, p.6081-6088, 2011.

MANN, H.B. Non Parametric Test Against Trend. Econometrika, n.13, p.245-259, 1945.

MARENGO, J. Variations and change in South American streamflow. Clim. Change, n.31, p.99-117, 1995.

MARENGO, J.A. Mudanças climáticas globais e seus efeitos sobre a biodiversidade: Caracterização do clima atual e definição das alterações climáticas para o território brasileiro ao longo do séc XXI. Brasília: MMA, 2006. 201p.

MARENGO, J.A.; ALVES, L.M. Tendências hidrológicas da bacia do rio Paraíba do Sul. Revista Brasileira de Meteorologia, n.20, v.2, p.215-226, 2005.

MCCARTHY, J.J. Climate change 2001: impacts, adaptation, and vulnerability: contribution of Working Group II to the third assessment report of the Intergovernmental Panel on Climate Change. London: Cambridge University Press, 2001. MELLO-THÉRY, N.A. Meio ambiente, globalização e políticas públicas. Revista Gestão \& Políticas Públicas, v.1, n.1, p.133-161, 2011.

METZ, B. Climate change 2001: mitigation: contribution of Working Group III to the third assessment report of the Intergovernmental Panel on Climate Change. London: Cambridge University Press, 2001.

PFAFSTETTER, O. Classificação de Bacias Hidrográficas - Metodologia de Codificação. Rio de Janeiro, RJ: DNOS, 1989.

PETTITT A.N. A Non-Parametric Approach To The Change-Point Problem. Applied Statistics, n.28, p.126-135, 1979.

RAMSAR SECRETARIAT. COP8, DOC. 11 - Climate Change and Wetlands. 2002, 64p.

RIBEIRO, A.G. As escalas do clima. Boletim de Geografia Teorética, n.23, v.45-46, p.288-294, 1993. 


\section{ISSN: 1980-055x (Impressa) 2237-8642 (Eletrônica)}

RIBEIRO, R.L.F.; MINGOTI, S.A. Apresentando um programa computacional em R e Geo$\mathrm{R}$ para análise espaço-temporal via geoestatística. XIII SIMPEP, p.1-12, 2006.

RUBERT,O.A.V. Codificação automática de regiões hidrográficas utilizando sistemas de informação geográfica. Dissertação de mestrado. Viçosa: UFV, 2000. 79p.

SALATI, E.; VICTORIA, R.L.; MARTINELLI, L.A.; RICHEY, J.E. Forests: their role in global change, with special reference to the Brazilian Amazon. Proceedings of the Second World Climate Conference, p. 391-395, 1991.

SALVI-SAKAMOTO, L. L. A chuva na Bacia do Alto Paraguai: contribuição ao estudo de aspectos das flutuações interanuais durante o século XX. Tese doutorado, Universidade de São Paulo, 2001.

SETTE, D.M. O holorritmo e as interações trópico extratrópico na gênese do clima e as paisagens do Mato Grosso. Tese de doutorado, Universidade de São Paulo, 2000, 321p.

TARIFA, J.R. O sistema climático do pantanal. Da compreensão do sistema à definição de prioridades de pesquisa climatológica. In: Simpósio sobre recursos naturais e sócioeconômicos do Pantanal, v.1, p.9-27, 1986.

TOZATO, H.C., MELLO-THERY, N.A., DUBREUIL, V. Policy tools for the protection of migratory waterbirds in Ramsar PARNA Pantanal site (MR, Brazil) face the impacts of climate change and land use. In: Water resources and wetlands, International Conference, 2012, Tulcea. Târgoviste: Transversal, 2012, p.509-514.

WATSON, R.T., ZINYOWERA, M.C., MOSS, R. H. The regional impacts of climate change: an assessment of vulnerability. London: Cambridge University Press, 1998.

WATSON, R.T.; ALBRITTON, D.L.; DOKKEN, D.J. Climate change 2001: synthesis report. World Meteorological Organization, 2003.

WATSON, R.T.; NOBLE, I.R.; BOLIN, B.; RAVINDRANATH, N.H. (Eds.). Land use, landuse change and forestry. Summary for policymakers. London: Cambridge University Press, 2000.

WILHELMY, H. Das Grosse Pantanal, Umshau, n.18, p.555-559, 1958.

ZAVATTINI, J.A. A dinâmica atmosférica e a distribuição das chuvas no Mato Grosso do Sul. São Paulo, Tese de Doutorado, Universidade de São Paulo, 1990.

ZAVATTINI, J.A. As chuvas e as massas de ar no estado de Mato Grosso do Sul: estudos geográficos com vista à regionalização climática. São Paulo: Cultura Acadêmica, 2009. $214 p$. 